\title{
Thinning scenarios to reconcile biodiversity conservation and socio- economic co-benefits in protected forest of Vietnam: Effects on habitat value and timber yield
}

\author{
GIANLUCA SEGALINA ${ }^{1, \bullet}$, CUONG NGUYEN DANG ${ }^{2, v v}$, ROSARIO SIERRA-DE-GRADO ${ }^{1, \bullet \bullet \vee}$ \\ ${ }^{1}$ Sustainable Forest Management Research Institute, University of Valladolid. Avda de Madrid 44, 3004 Palencia, Spain. \\ •email: segalinagianluca@gmail.com,.vv rsierra@pvs.uva.es \\ ${ }^{2}$ Faculty of Forestry, Thai Nguyen University of Agriculture and Forestry, Vietnam. ${ }^{*}$ email: nguyendangcuong@ tuaf.edu.vn.
}

Manuscript received: 21 April 2020. Revision accepted: 15 May 2020.

\begin{abstract}
Segalina F, Dang CN, Grado RSD. 2020. Thinning scenarios to reconcile biodiversity conservation and socio-economic cobenefits in protected forest of Vietnam: effects on habitat value and timber yield. Asian J For 4: 22-35. Forest protection policy since the 1990 s in Vietnam has led to an overall increase in forest cover, but has also adversely impacted the livelihoods of local populations and has displaced deforestation to neighboring countries. As such, it is necessary to explore strategies to achieve sustainable utilization of tropical forests in a way that is compatible with the preservation of biodiversity. One of which is by selective thinning. This study aimed to analyze the habitat and economic value of the trees in a forest block, then compare the effects of four thinning scenarios on profit and habitat value. We simulated four thinning scenarios and assessed their effects on biodiversity and economic value. The scenarios were defined according to two criteria: tree dominance and tree habitat value. The study took place in a one-hectare plot of marteloscope located in a naturally regenerated mixed forest enriched with native tree species. The habitat value, evaluated by tree-related microhabitats, was used as a proxy for biodiversity. In our study, as many 58 different tree species were found within the marteloscope. Co-dominant trees with a higher diameter at breast height yielded the highest average habitat value, which coincides weakly with findings in temperate forests. In our study, the biodiversity conservation criterion had only a marginal effect on economic benefit. Both results together show that a meeting point between profitability and biodiversity conservation is possible.
\end{abstract}

Keywords: Biodiversity, forest policy, marteloscope, thinning, tree-related microhabitats, tropical forest

Abbreviations: TreMs: Tree-related microhabitats, DBH: diameter at breast height, S1, S2, S3, S4: Scenario 1,2,3,4

\section{INTRODUCTION}

Tropical forests comprise the greatest biodiversity on the earth (Gardner et al. 2009; Gibson et al. 2011), yet their conservation is the worst compared to other ecosystems (Bradshaw et al. 2009). Because of many natural ecosystems in the tropics have been lost or degraded, biodiversity conservation in these regions largely depends on the management of human-modified ecosystems, imposing challenges for researchers and forest managers (Gardner 2009). Nonetheless, the complexity of ecological processes in tropical forests makes it difficult to carry out forest management activities with considerations on biodiversity conservation (Magurran et al. 2003).

In recent decades, interest in biodiversity conservation through preserving and expanding forest cover has increased (Rocchini and Ricotta 2007), although the progress is unequal among countries, especially in the tropics (Wilson et al. 2016). Deforestation is still a big threat to some tropical countries, while others are experiencing overall forest growth (Pekka et al. 2006). In Vietnam, forest protection is the objective of the Vietnam National Forest Policy enacted since the 1990s. This policy has led to a remarkable increase in the national forest area, but also to a huge increase in wood imports from other countries such as Cambodia and Thailand (International Trade Centre 2019), causing a displacement of deforestation (Meyfroidt 2009).

The Vietnamese Forest Protection and Development Law in 1991 classifies the forest of the country into three types: special-use, protection, and production forests. Special-use forest includes protected areas and they have a principal role in meeting the obligations of the Convention on Biodiversity (United Nations 1992). In special-use and protection forests, timber extraction and forest resources utilization are largely limited to a few specified non-timber forest products (Prime Minister of Vietnam 2007), giving rise to a range of problems and conflicts (Kimdung et al. 2013; Thi Hoan 2014) including the more dependence of local people on state funds (Tan 2006). At the same time, budget allocation to support such policy is limited (Hoan 2014) and revealed to be not effective enough to eliminate illegal logging (Chatham House 2020), so a different type of forest management involving sustainable use may provide win-win solutions, i.e. forest management that can achieve both biodiversity conservation and socio-economic benefits (Quang and Ph 2005). Between the extremes of total forest protection (i.e. being banned from any kind of use) and plantations forestry (i.e. intensive management with reduced biodiversity), there may be an alternative of 
sustainable use and management of forests that can provide some income without compromising conservation of biodiversity.

We hypothesized that some forest management operations could be undertaken without heavily affecting forest biodiversity and functioning. One of the proposed strategies is through stand thinning based on criteria that favor biodiversity conservation. This would provide local people with additional income while taking a step towards sustainable management of protected forest areas, as indicated in United Nations Sustainable Development Goal 15 (United Nations 2015). To aid decision-making for thinning in a forest, it is necessary to evaluate trade-offs between the economic value of each tree and its value for biodiversity. This study aimed to analyze the habitat and economic value of the trees, then compare the effects of four thinning scenarios on profit and habitat value. To achieve this, we used TreMs framework, which is defined as indirect indicators for the specialized species that use them as substrates or habitat at least for a part of their lifecycle (Larrieu et al. 2018; Santopuoli et al. 2019). These include cavities, wounds, deadwood and other features as meaningful bioindicators for the habitat value of the tree. We expect the results of this study is to contribute to the management and conservation of secondary tropical forests in Vietnam.

\section{MATERIALS AND METHODS}

\section{Study area}

The study area was located at the Me Linh Station for Biodiversity (coordinates: $21^{\circ} 23^{\prime} 19^{\prime \prime}$ to $21^{\circ} 24^{\prime} 02^{\prime \prime} \mathrm{N}$, and $105^{\circ} 42^{\prime} 45^{\prime}$ "to $\left.105^{\circ} 42^{\prime} 50^{\prime \prime} \mathrm{E}\right)$, about $50 \mathrm{~km}$ from Hanoi and nearby Dai Lai tourist site in Ngoc Thanh Commune, Phuc
Yen District, Vinh Phuc Province (Northern Vietnam). It borders Tam Dao National Park in the West and is considered as a green buffer zone of the National Park. The elevation of the station stretches from 60 to $500 \mathrm{~m}$ above sea level and the extent comprises 170 ha, consisting of 69 ha of secondary forest, 30 ha of plantation forest, 68.3 ha of grassland, rocky streams, and ponds, and 3 ha of administration area. The natural vegetation is tropical rain evergreen closed forest. The weather is tropical and varies throughout the year with a seasonally wet climate. The mean annual rainfall is $1600 \mathrm{~mm}$ and the rainy season is from April to October with over $90 \%$ of rain occurring during this period ( Vu 2008). (Figure 1). The Melinh Station was established in 1999 and belongs to the Institute of Ecology and Biological Resources (Hanoi), which supports education and scientific research. It boasts rich plant diversity with 1,227 vascular plant species, 670 genera, 172 families, and 6 divisions.

In 1992, on the flat edges of this site, the natural vegetation was clear-cut to plant Acacia spp and Pinus massoniana. These forest plantations failed and naturally grow vegetation has since been generated occupied by light-demanding plants such as Liquidambar formosana, Cratoxylum cochincinensis, Aporosa dioica, and Wendlandia paniculata. In 2002, the shrub and grass layers on the area were clear-cut and native species were planted for enrichment. Among them were Erythrophleum fordii, Lithocarpus corneus, Pelthophorum dasyrrhachis, Machilus bonii, Aphanamixis grandiflora, Dipterocarpus retusus and others. Today, there are various kinds of ecosystems in the Melinh station, including the flat area that hosts plantations of tea trees, medicinal plants, and regenerated forest, while natural forest occurs on the slopes.
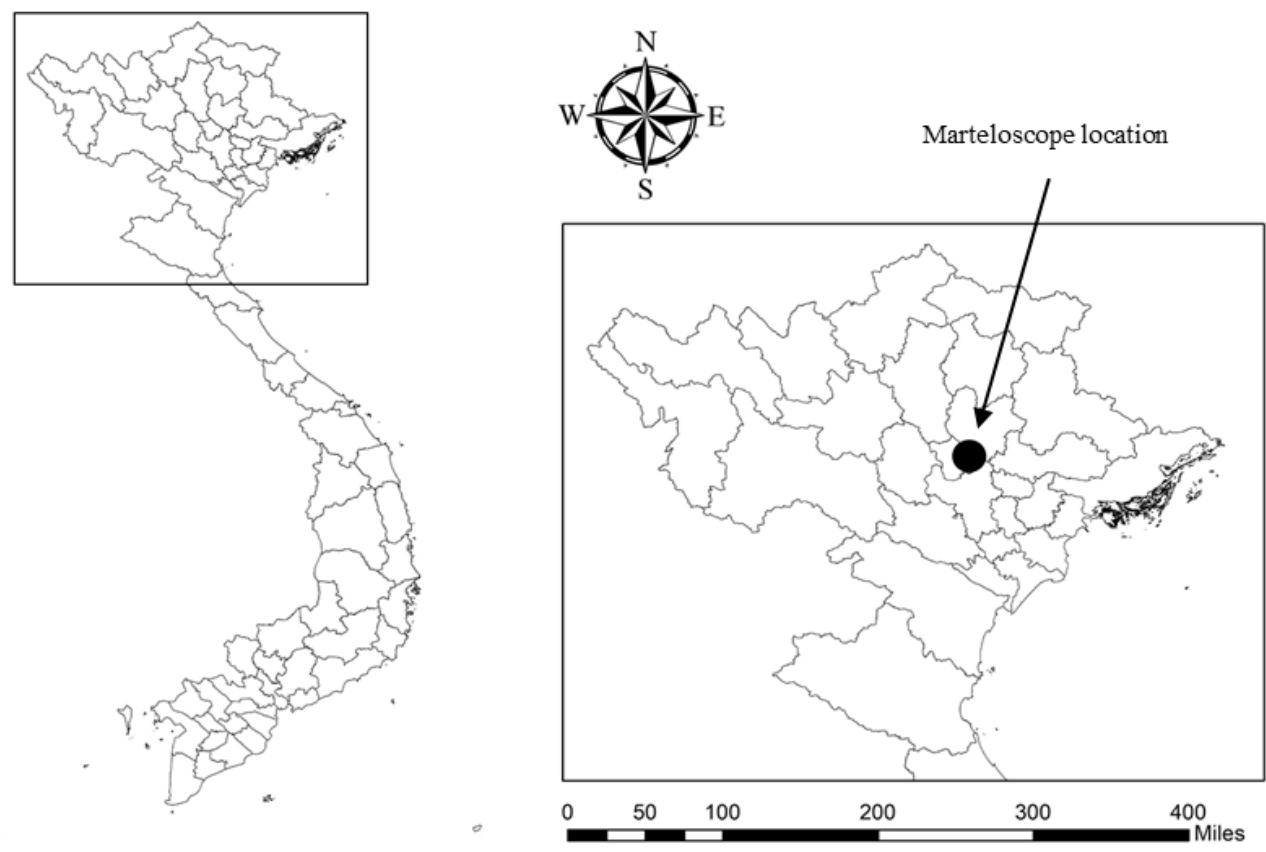

Figure 1. Location of the Melinh Station for Biodiversity in Phúc Yên municipality, Vinh Phuc Province (Northern Vietnam) 


YN
\begin{tabular}{|l|l|l|l|}
\hline 4.1 & 4.2 & 4.3 & 4.4 \\
\hline 3.1 & 3.2 & 3.3 & 3.4 \\
\hline 2.1 & 2.2 & 2.3 & 2.4 \\
\hline 1.1 & 1.2 & 1.3 & 1.4 \\
\hline
\end{tabular}

Figure 2. Diagram of the marteloscope plot at the Melinh Station for Biodiversity, Northern Vietnam

\section{Procedures}

Marteloscope set-up

A marteloscope is a permanent plot of 1 ha (Schuck et al. 2015) combined with a "computer compiler" intended to simulate the immediate effect of a harvesting choice (Soucy 2014). It must meet three criteria: be representative of the forest heterogeneity including gaps, different kinds of vegetation and forest stages; the selected forest must show a certain "need" to be managed in the sense that it has to be suitable for virtual management exercises; to renounce to the real management for at least 10 years justifying the set-up cost and ensuring the medium-term site usage (Schuck et al. 2015).

In 2018, a marteloscope was established under the framework of the BioEcoN Project (Erasmus +, Capacity Building in the field of Higher Education), by the Thai Nguyen University of Agriculture and Forestry, a partner in this Project (http://bioecon.eu/). The entire plot (1 ha) belongs to the Melinh Station for Biodiversity and has good accessibility. Its altitude ranges from 69 to 83 m.a.s.l.

The plot was divided into 16 square subplots measuring $25 \times 25$ meters each (Figure 2). The position of the first corner of the plot (1.1) was established by 2 reference points outside the plot, using GPS 64sx. Starting from the first corner, the coordinates of each corner of each subplot were then recorded. The marteloscope area is almost entirely flat, except for subplots 1.1, 2.1, and 3.1 which are at the base of a slope.

\section{Data collection}

All trees were recorded by two teams of four people. All the living trees with a diameter at breast height (DBH) equal to or greater than $7 \mathrm{~cm}$ were considered. Because the average DBH was very small, the decision was made to consider trees from $7 \mathrm{~cm} \mathrm{DBH}$ instead of $9 \mathrm{~cm}$ prescribed by Soucy (2014). The DBH was measured indirectly using tape. Tree height at crown base and height at largest crown width diameter were measured using Terinox LRF 1800 and 1200 along with the slope angle.
The recorded variables included tree id (number), tree species, DBH (cm), slope angle (degrees), tree total height $(\mathrm{m})$, tree height to crown base $(\mathrm{m})$, timber quality, stem straightness, potential use, tree health status, tree microhabitats. All trees were geolocated. Timber quality and health status were assigned on a scale from one (good) to three (bad), according to marteloscope installation protocol criteria (Soucy 2014). Stem straightness was ranked from one (straight) to six (very curved). The species name of the tree was determined by experts, and the potential use of each tree species was assigned according to information contained in the reference book "Tên cây rừng Việt Nam" (The Names of Forest Plants in Vietnam) (Ministry of Agriculture and Rural Development 2000). We identified a total of 58 tree species in the plot; the 15 most abundant ones are reported in Figure 3.

Subsequently, timber volume was calculated using the formula developed by Hinh (2012) which has been applied to natural forests in Northern Vietnam:

$$
V\left(m^{3}\right)=0.00006341 * \mathrm{DBH}^{1.9786} * H^{0.9697}
$$

Where:

$V=$ Tree timber volume

$\mathrm{DBH}=$ Diameter at breast height

$\mathrm{H}=$ Total height of the tree

We used TreMs, which are "indirect indicators for the specialized species that use them as substrates or habitat at least for a part of their life-cycle" (Larrieu et al. 2018). These include cavities, wounds, deadwood and other features as meaningful bioindicators for the habitat value of the tree. The TreMs classification used for data collection is shown in Table 1. We followed the criteria of Larrieu et al. (2018), except that the height limit for TreMs observation was $3 \mathrm{~m}$ instead of $5 \mathrm{~m}$. The decision was based on the high forest density ( 805 trees/ha), with thick under-canopy vegetation and abundant liana. These reduce the visibility of the upper part of the trunks, making TreMs evaluation potentially misleading.

All the data were collected in February 2019, except for TreMs, which were recorded in May 2019.

\section{Economic valuation}

Finding information to assign an economic value to the trees within the marteloscope required a literature review process. We found that the Ministry of Agriculture and Rural Development \& Ministry of Trade, General Department of Customs, Vietnamese Government 1995, published a joint circular concerning simplification and regulation of timber trade. They identified the 354 least endangered most valuable tree species on the market and divided them into eight timber classes. After publication of that document, Vietnamese enterprises could set buying prices according to the timber class, thereby overcoming the need to evaluate each tree species every time. 


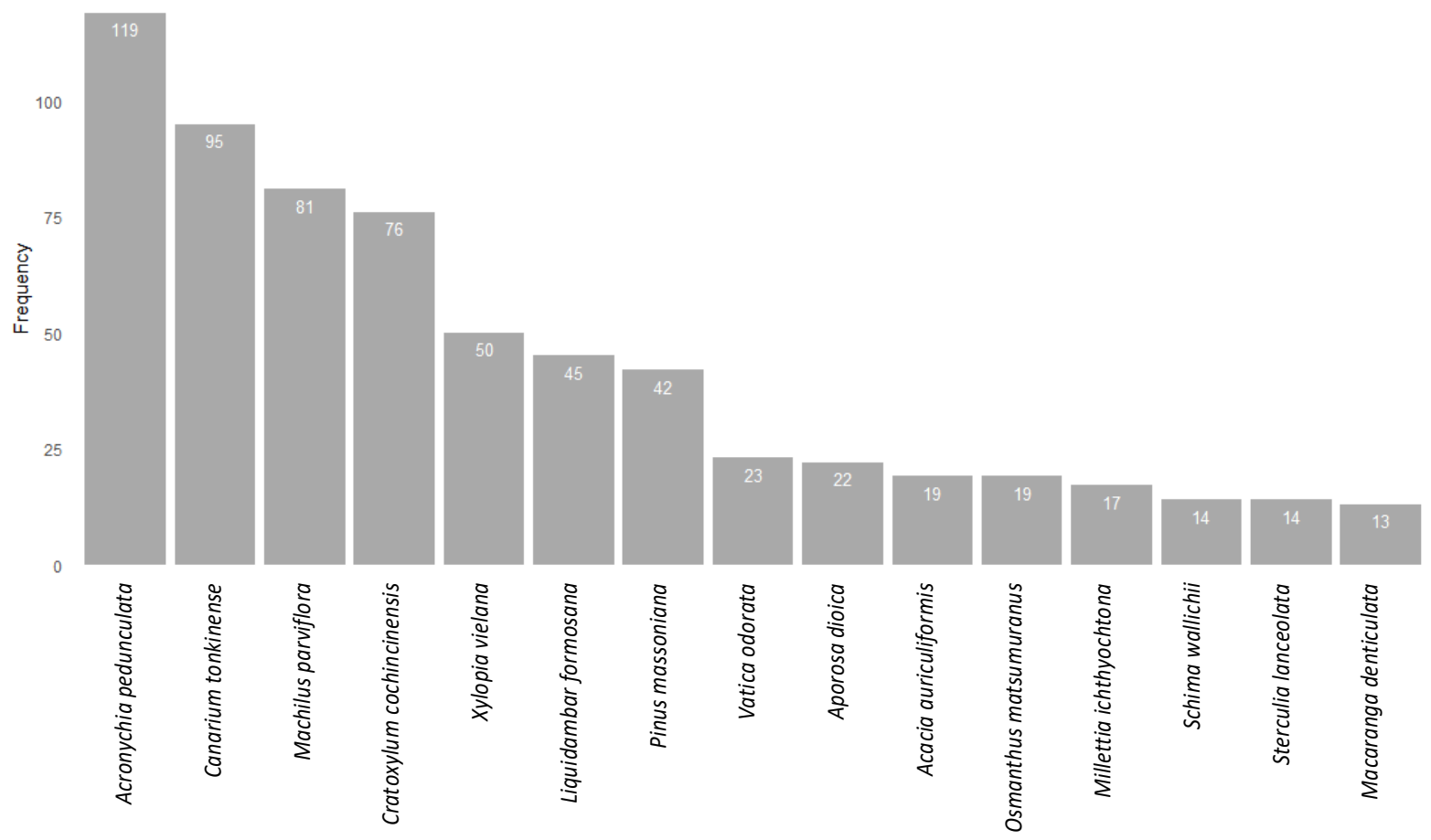

Figure 3. Frequency distribution of 15 most abundant tree species within the one-hectare marteloscope. As many 58 tree species were found in the plot, comprising a total of 805 individuals.

After that, we looked for the prices that Vietnamese timber companies pay for each timber class. We selected the price list provided by the Chúc mừng năm mới company website because it referred to Nguyễn (2018), which was the most up-to-date, and most comprehensive price list. The list was consulted on 16 June 2019 and shows prices for standing trees in different timber classes (Table 2). It did not provide any information about possible reductions of the buying price depending on the wood quality (straightness and presence of defects) or tree diameter, for example. The search to find more precise pricing proved unsuccessful, forcing us to rely on the data of Nguyễn (2018). We calculated the total economic value of the trees by multiplying the total amount of wood $\left(\right.$ in $^{3}$ ) in each timber class by the relative buying price.

\section{Data analysis \\ Habitat value}

The data analysis was done using $\mathrm{R}$ software v.3.5.3. The first part involved assigning each tree a habitat value, calculated for each tree based on the number of recorded TreMs, using the formula proposed by Kraus et al. (2018). The calculation considers the relative rarity of habitat in the forests and the time span needed for it to develop.

$$
H_{i}=\sum_{j=1}^{n} N_{j} \times s_{j} \times\left(R_{j}+D_{j}\right)
$$

Where: $H_{i}$ is the habitat value of tree $i, N_{j}$ the number of microhabitat type $j, \mathrm{R}$ is the value of the rarity of a TreMs,
$\mathrm{D}$ is the value of the time that a microhabitat takes to develop or to be available, and S is the size score (physical size of a TreMs) within a TreMs type (see Tables 1 and 3). The result $H_{i}$ is then expressed in "habitat points".

The R-value was assigned by counting the frequency of each type of TreMs and then rescaling the result from one to five, where one is the minimum rarity and maximum frequency, and five is the maximum rarity and the lowest frequency.

\section{Thinning scenarios}

We simulated four thinning operations to compare their effects on basal area and tree distribution, along with economic value and habitat value. Two criteria were used to define the harvesting (Table 4): the relative position of trees in crown classes (codominant or suppressed) and the habitat value of the tree (any or low habitat value). Those criteria were applied at the subplot level, which means that each thinning simulation was implemented individually for each of the 16 subplots. The quantity of basal area removed was always $30 \% \pm 1 \%$ of the total.

Using five as a reasonable number for tree diversity conservation, we excluded species within the marteloscope with five individuals or less from the thinning simulations. Accordingly, each simulation spared at least five individuals of each tree species at the plot level. We also excluded all threatened and endangered species, based on the IUCN red list of threatened species (IUCN 2019). After that, we fitted linear models for each scenario, in which the habitat value of the removed trees is a function of tree DBH. 
Table 1. Illustrations of TreMs types in European temperate and Mediterranean forests from Larrieu et al. (2018) were used for data collection and to derive the habitat value of the trees.

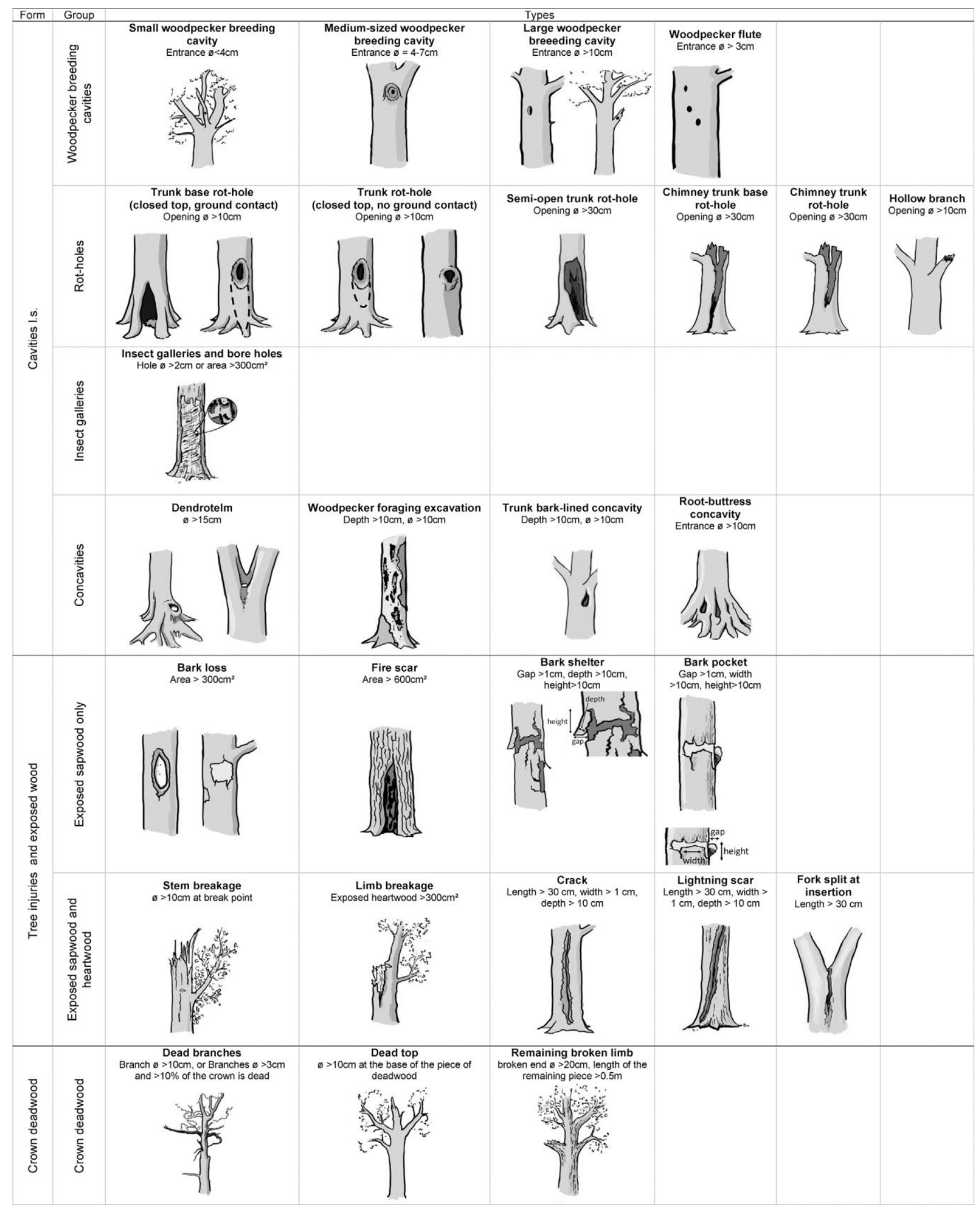




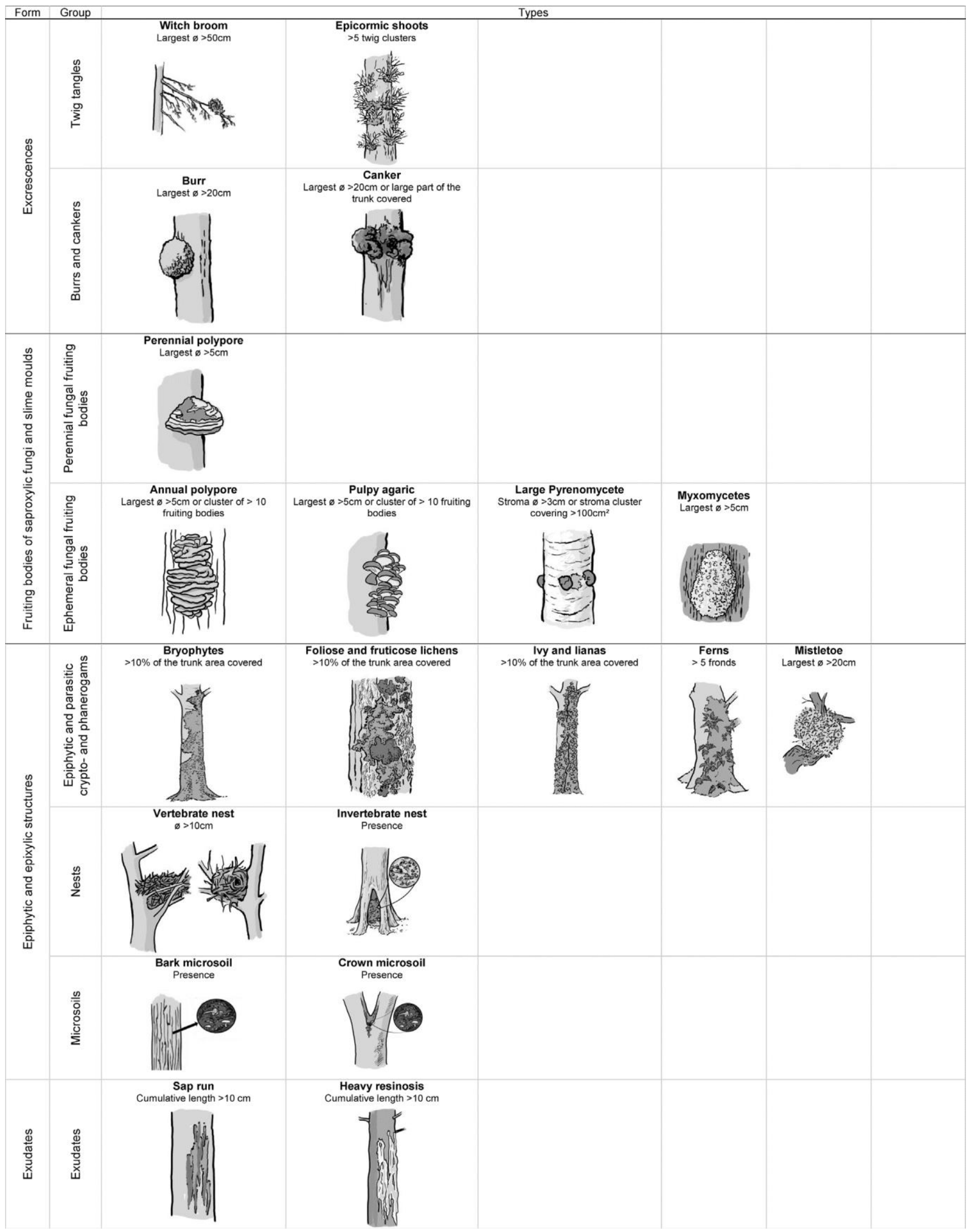


Table 3. The criteria of R, D and s for evaluation of TreMs

\begin{tabular}{lllc}
\hline \multicolumn{1}{c}{ Rarity gradient (R-value) } & \multicolumn{1}{c}{ Development time (D-value) } & Size (s) \\
\hline Very common & Fast or linked to a very common event & $\emptyset \leq 4 \mathrm{~cm}$ \\
Common & Fairly fast or linked to a fairly common event & $4 \mathrm{~cm}<\phi \leq 10 \mathrm{~cm}$ \\
Fairly rare & From fairly slow to slow or linked to an uncommon event & $10 \mathrm{~cm}<\phi \leq 15 \mathrm{~cm}$ \\
Rare & Slow or linked to a rare event & $15 \mathrm{~cm}<\phi \leq 20 \mathrm{~cm}$ & 2 \\
Very rare & Very slow or linked to a very rare event & $\emptyset>20 \mathrm{~cm}$ & 4 \\
\hline
\end{tabular}

Table 2. Timber groups and relative average prices per cubic meter of Roundwood in 2018 in Vietnamese and USA currencies.

\begin{tabular}{lcc}
\hline Wood type & $\begin{array}{c}\text { Price }\left(\mathbf{m}^{\mathbf{3}} \text { roundwood) }\right. \\
\text { in VND }\end{array}$ & $\begin{array}{c}\text { Price }\left(\mathbf{m}^{\mathbf{3}} \text { roundwood }\right) \\
\text { in USD }\end{array}$ \\
\hline Group 1 & $3,600,000.00$ & 154.8 \\
Group 2 & $2,500,000.00$ & 107.5 \\
Group 3 & $2,700,000.00$ & 116.1 \\
Group 4 & $1,900,000.00$ & 81.7 \\
Group 5 & $1,700,000.00$ & 73.1 \\
Group 6 & $1,300,000.00$ & 55.9 \\
Groups 7 \& 8 & $1,100,000.00$ & 47.3 \\
\hline
\end{tabular}

Table 4. Criteria used to simulate the harvesting operations (tree removal)

\begin{tabular}{lll}
\hline Scenario & Criterion1 & Criterion 2 \\
\hline S1 & Suppressed trees & Any habitat value \\
S2 & Suppressed trees & Low habitat value \\
S3 & Codominant trees & Any habitat value \\
S4 & Codominant trees & Low habitat value \\
\hline
\end{tabular}

\section{RESULTS AND DISCUSSION}

\section{Results}

Forest inventory

The inventory revealed 805 trees with a DBH of $7 \mathrm{~cm}$ or higher (Figure 4). The tree species with the largest DBH was Liquidambar formosana $(50.4 \mathrm{~cm})$, followed by Pinus massoniana $(47 \mathrm{~cm})$. The total volume of wood in the plot was estimated to be $89.2 \mathrm{~m}^{3}$, which when divided by the number of trees, gave an average wood volume of $0.11 \mathrm{~m}^{3}$ per tree. The amount of valuable timber was $48.2 \mathrm{~m}^{3}$. The only endangered or vulnerable tree species found in the marteloscope was Erythrophleum fordii (IUCN 2019), which had 5 individuals. All the other species are classified in 'least concern' or 'data deficient' categories.

The spatial distribution of tree species should be noted since it was visually apparent that Pinus massoniana was grouped mainly on one side of the plot (Figure 5). The trees found in the marteloscope has grown up almost entirely since the year 2002, when shrubs were removed and native trees were planted to enrich the forest composition. Using the volume of $89.2 \mathrm{~m}^{3}$, the mean annual increment since 2002 has been $5.25 \mathrm{~m}^{3} /$ year.

\section{TreMs and tree habitat value}

A total of 4755 TreMs of diverse types were found in the marteloscope. The most abundant TreMs types were the epiphytic and parasitic cryptogams and phanerogams, with
2079 recorded. These bryophytes, foliose and fruticose lichens, along with ivy and lianas, accounted for $43 \%$ of the total recorded TreMs. However, some of the TreMs described in Larrieu et al. (2018) were not present at all in our plot. There were no woodpecker cavities of any kind, fire scars, perennial polypores, witches' broom, mistletoe, or ferns. Similarly, we found no vertebrate nests, but this was probably due to low visibility in the forest.

We observed insect holes on three trees: one Itea chinensis and two Archidendron clypearia. Each tree had about 50 holes with diameters equal to or greater than $2 \mathrm{~cm}$ (below the $3 \mathrm{~m}$ height threshold). Those 3 trees had very low DBH (less than $10 \mathrm{~cm}$ ) and the highest number of recorded TreMs $(67,54$, and 53 respectively). Notably, the Itea chinensis was the tree with the highest habitat value (2296 habitat points) and the Archidendron clypearia trees were among the top 15 trees with highest habitat values (1164 and 1195 habitat points). We found only 3 trees with no TreMs, belonging to 3 different species: Cratoxylon cochinsinensis, Acacia auriculiformis, and Machilus parviflora, with $\mathrm{DBH}$ of $9.8,17.5$ and $15.8 \mathrm{~cm}$ and total height of 7.5, 11, and $9.2 \mathrm{~m}$, respectively.

Generally, the larger TreMs, such as the semi-open trunk rot-hole, dead top, or chimney trunk base rot-hole, were also less frequent than the small TreMs (bark shelter and dead branches) or biotic TreMs. Bryophytes, foliose and fruticose lichens, insect galleries and boreholes, invertebrate nests, ivy, lianas, and resin flow were the most abundant biotic TreMs. For example, we found only 1 chimney trunk base rot-hole, 1 trunk bark-lined concavity and 1 annual polypore, hosted in an Acronychia pedunculata (10.3 cm DBH and $6.43 \mathrm{~m}$ total height), Xylopia vielana $(7.8 \mathrm{~cm} \mathrm{DBH}$ and $8 \mathrm{~m}$ total height) and a Liquidambar formosana $(20.3 \mathrm{~cm}$ DBH and $9 \mathrm{~m}$ total height). The total height of those trees was slightly below the average (Table 5), while their DBH was above average (Figure 4) except for Xylopia vielana, with a DBH among the lowest measured.

\section{Economic value}

We identified 360 trees with associated economic value (Table 6), representing $45 \%$ of the total number of trees (805) in the marteloscope. However, occurrence was low for many of those species, making them non-harvestable from a sustainability or conservation perspective. If there are only one or two trees of a species, we assume that harvesting may significantly reduce their chances of reproduction.

The most abundant tree species found in the plot was Acronychia pedunculata (Table 6), with 119 individuals. 
This species is mainly used for traditional medicine (Ministry of Agriculture and Rural Development 2000) and does not appear in the joint circular of the Vietnamese government, suggesting that its timber quality is relatively poor. Even if Acronychia pedunculata timber has some use-value, and though it was used for construction in the past (Ministry of Agriculture and Rural Development 2000), our analysis indicated that it is not marketable and therefore its economic value equals to zero. Within the entire plot, we found only one tree belonging to Timber Class 1 and none belonging to Timber Class 2 which are the most valuable timber classes (Table 6).

\section{Thinning scenarios}

At the time of data collection, the estimated tree economic value for the marteloscope was 3,219 USD, the total basal area was $14.75 \mathrm{~m}^{2}$ and the total habitat value was 189,360 habitat points. We observed a big difference in the removed habitat value between Scenario 1 (S1) and $\mathrm{S} 2$, reflecting variation in both the quantity and quality of removed TreMs (Figure 6). The removed economic value in S2 was higher than in S1, though timber volume was the same $\left(23 \mathrm{~m}^{3}\right)$. Also significant was the difference between the number of trees removed in $\mathrm{S} 1$ and $\mathrm{S} 2$, which amounted to 324 and 288 trees, respectively.

The difference between the two criteria was also visible in S3 and S4, where the number of thinned trees was higher in S4 than in S3. In S4, the removed habitat value was much lower than in $\mathrm{S} 3$, and the economic value in $\mathrm{S} 4$ was close to that of $\mathrm{S} 2$. The highest removed economic value occurred in S3 but no big differences were observed among the 4 scenarios, where revenues ranged from 500 to 600 USD.

Figure 7 shows the linear regressions of $\mathrm{DBH}$ as function of the habitat value of the marked trees in S1, S2, S3, and S4. When looking at the average habitat value of all the marked trees within each scenario, we find that the expected DBH value (intercept) is smaller in S1 than in S3. Its slope, though significant in both cases, is very small and positive (i.e. 0.0026 for $\mathrm{S} 1$ and 0.0062 for $\mathrm{S} 3$ ). This means that the relationship between $\mathrm{DBH}$ and habitat value is very small, but habitat value grows when DBH grows. To assist in the interpretation of the results, we also calculated the average habitat value of the removed trees for each scenario and found that S3 and S4 gave the highest values (Table 7).

In Figure 5, it is possible to appreciate the spatial distribution of removed trees in the different scenarios, compared to the current situation. We can also see that the trees with the greatest basal area often have the highest economic value as well. For example, Pinus massoniana are very large, tall trees (Figures 4 and 5) with high amounts of timber, which leads to high economic value. At the same time, their habitat value is low because they have few TreMs.

Table 5. Summary of the total height of the trees in the marteloscope

\begin{tabular}{llllll}
\hline \multicolumn{7}{c}{ Summary of total height $(\mathbf{m})$} \\
\cline { 1 - 3 } Min. & 1st Qu. & Median & Mean & 3rd Qu. & Max. \\
2.14 & 7.700 & 9.440 & 9.713 & 11.459 & 32.190 \\
\hline
\end{tabular}

Table 6. Number of species, names of tree species and number of individuals of each species in the marteloscope plot ordered by frequency and timber class according to the Vietnamese Government Joint Circular of 22 December 1995

\begin{tabular}{lcc}
\hline \multicolumn{1}{c}{ Tree species } & $\begin{array}{c}\text { Number of } \\
\text { individuals }\end{array}$ & $\begin{array}{c}\text { Timber } \\
\text { class }\end{array}$ \\
\hline Acronychia pedunculata & 119 & \\
Canarium tonkiense & 95 & 6 \\
Machilus parviflora & 81 & 6 \\
Cratoxylum cochinsinensis & 76 & \\
Xylopia vielana & 50 & \\
Liquidambar formosana & 45 & 5 \\
Pinus massoniana & 42 & 5
\end{tabular}

Vatica odorata

Aporosa dioica

Acacia auriculiformis

Osmanthus matsumuranus

Millettia ichthyochtona

Schima wallichii

Sterculia lanceolata

Macaranga denticulata

Canthium horridum

Styrax tonkinensis

Archidendron clypearia

Cansjera rheedii

Elaeocarpus griffithii

Eucalyptus citriodora

Chaetocarpus castanocarpus

Phoebe tavoyana

Canarium album

Engelhardtia roxburghiana

Ficus hispida

Acacia mangium

Clausena excavata

Erythrophleum fordii

Itea chinensis

Mallotus mollissimus

Actinodaphne pilosa

Choerospondias axillaris

Lithocarpus fissus

Clausena dunniana

Hydnocarpus hainamensis

Michelia balansae

Toxicodendron succedanea

Bischofia javanica

Carallia diplopetala

Castanopsis indica

Diospyros apiculata

Endospermum chinense

Eurya ciliata

Garcinia hainanensis

Garcinia multiflora

Hymenodictyon orixense

Litsea cubeba

Litsea umbellata

Memecylon edule

Mischocarpus pentapetalus

Peltophorum dasyrrhachis

Stereospermum colais

Symplocos laurina

Wendlandia paniculata

Wrightia pubescens

Xanthophytum polyanthum

7

6

8

8

8

6

7

6

7

7

3

1

Zanthoxylym avicennae 


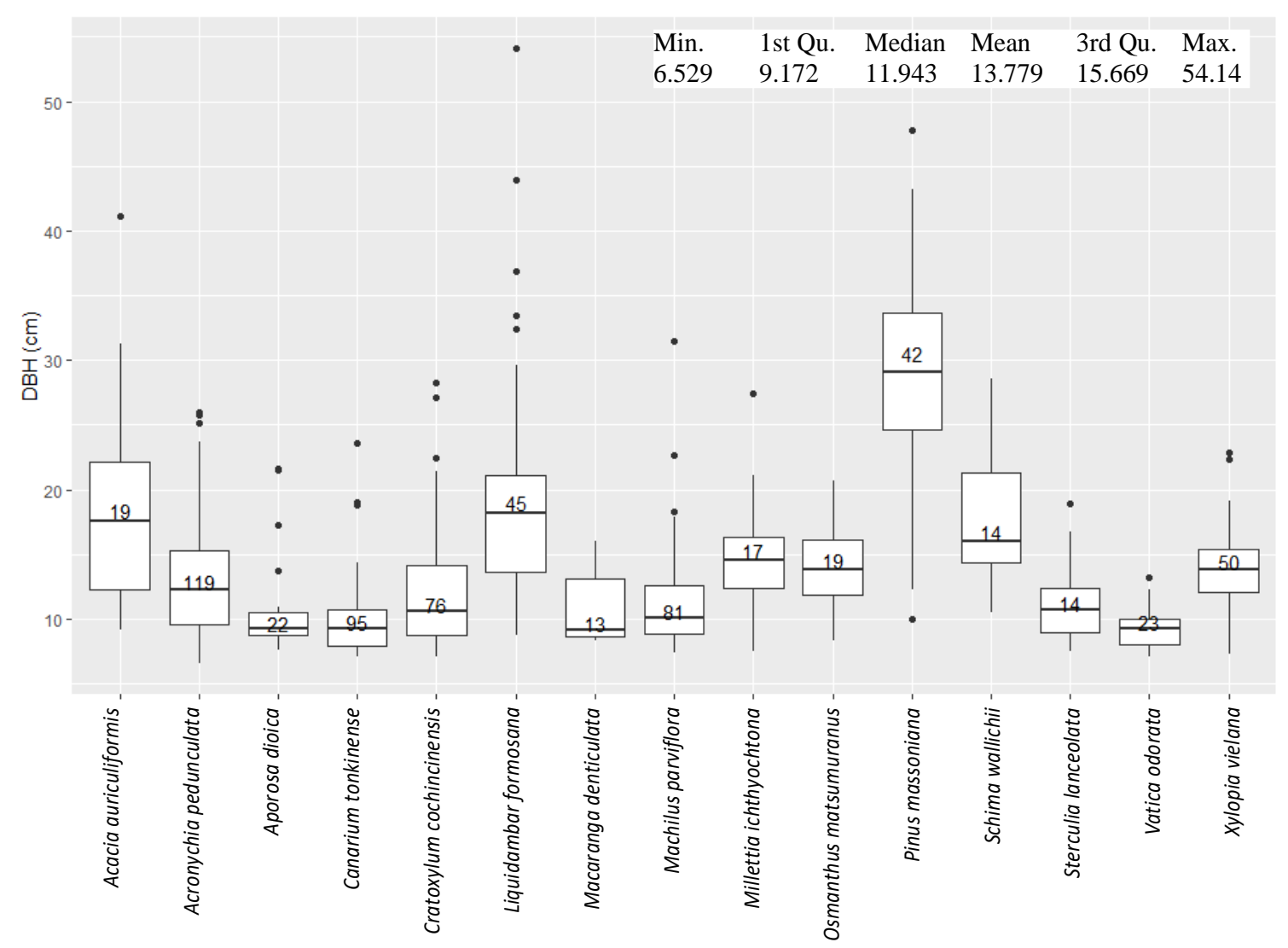

Figure 4. Boxplot of the DBH of the 15 most abundant tree species in the marteloscope, indicating the number of individuals and the mean DBH (line inside the box) of each of those species. Summarized above are the minimum, first quartile, median, mean, third quartile and max for $\mathrm{DBH}$

Table 7. Average habitat value (habitat points) of the marked trees for each thinning scenario.

\begin{tabular}{cc}
\hline Scenario & Mean tree habitat value \\
\hline 1 & 199.50 \\
2 & 161.37 \\
3 & 230.80 \\
4 & 177.86 \\
\hline
\end{tabular}

\section{Discussion}

\section{Forest inventory and TreMs}

The number of TreMs recorded in the marteloscope in this study (4755) is more than 6 times higher than the number recorded in the study of Santopuoli et al. (2019) for the Mediterranean region (754). To the best of our knowledge, this is the first study of its kind in a Southeast Asian tropical forest. Another difference between the two studies is the most abundant TreMs category: in our case, $43 \%$ of TreMs corresponded to epiphytic and parasitic cryptogams and phanerogams, while in the Mediterranean study, $42 \%$ of TreMs were cavities. The similar quantitative approach implemented in both studies uncovers important differences between Mediterranean and tropical forests in terms of quantity and type of microhabitats. More precisely, the epiphytic and parasitic cryptogams and phanerogams category included 895 bryophytes, 888 foliose and fruticose lichens, and 701 ivy and lianas. While bryophytes and lichens simply live on the bark of the trees, ivy and lianas rely on the tree stem for structural support while twisting around the tree stem in search of light. Furthermore, the same liana can twist around and bond to more than one tree, making thinning operations harder. They can also develop stems that are sometimes thicker than the supporting tree stem (Jacobs 1976). In our study, lianas were considered as TreMs, so their timber volume, basal area, and the TreMs they host were not considered.

The most recurrent TreMs type on the same tree was the insect borehole, which occurred in 3 cases. It was unexpected to find that the pests had attacked each of the three trees - a single Itea chinensis and two Archidendron clypearia - more than 50 times without attacking the surrounding trees or other trees of the same species (altogether, we found five Itea chinensis and ten Archidendron clypearia trees). As mentioned above, the $\mathrm{DBH}$ of those trees was less than $10 \mathrm{~cm}$ and their habitat value was the highest among all the recorded trees. This shows that despite the low rarity of insect galleries and holes, they can contribute significantly to the habitat value of the trees. The reason for the high occurrence of these TreMs types remains unexplored and further research is needed to clarify their causal dynamics. 
Basal area
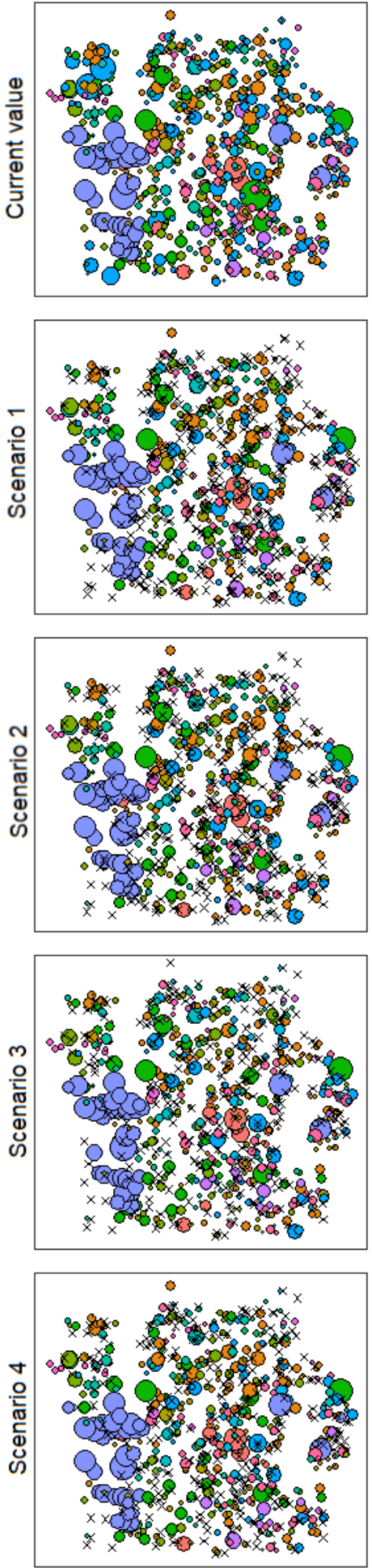

Economic value
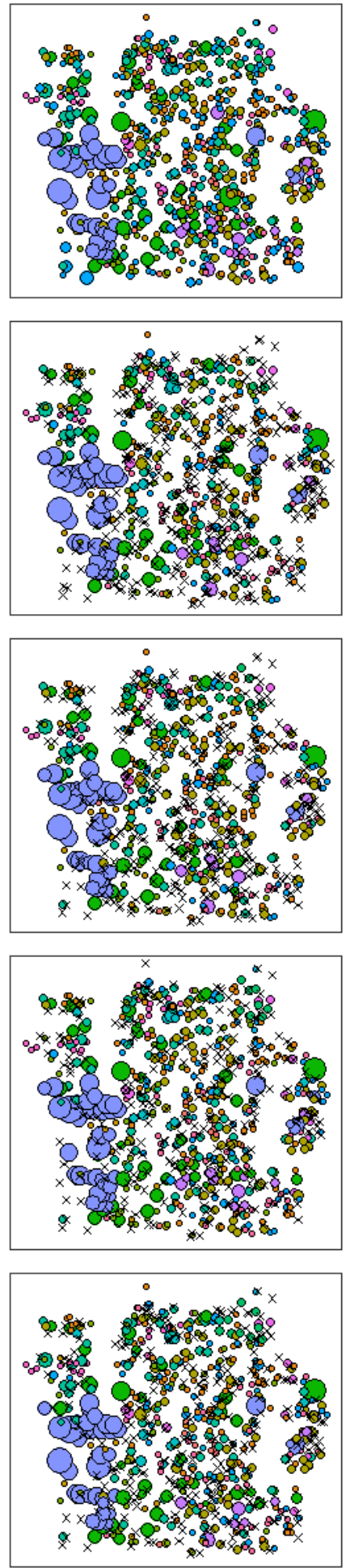

$\bigcirc$ Acacia auriculiformis
Acronychia pedunculata
Aporosa dioica
Canarium tonkiense

Cratoxylum cochincinensis

Millettia ichthyochtona

Osmanthus matsumuranu

Other species

$\bigcirc$ Pinus massoniana
Habitat value
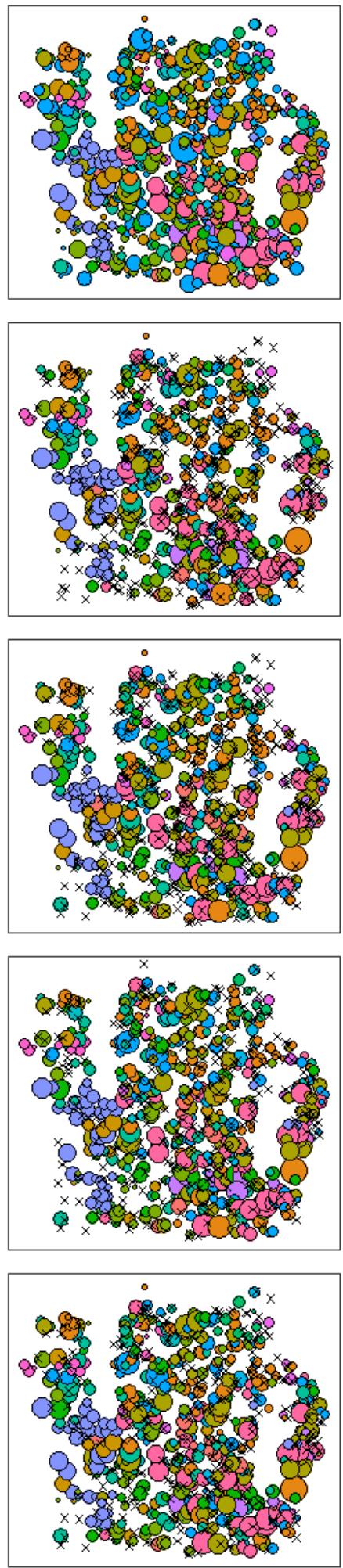

Schima wallichii $\times$ Marked trees

Sterculia lanceolata

Vatica odorata

Xylopia vielana

Figure 5. Forest intervention scenarios show the tree spatial distribution inside the marteloscope by considering basal area, economic value, and habitat value. The colors indicate the 15 most abundant tree species while the rest are grouped under the name "other species" to simplify viewing. Removed trees are marked with an " $x$ ". The dimension of the circle reflects basal area $\left(\mathrm{m}^{2}\right)$ in the first column, economic value (USD) in the second column and habitat value (habitat points) in the third column 

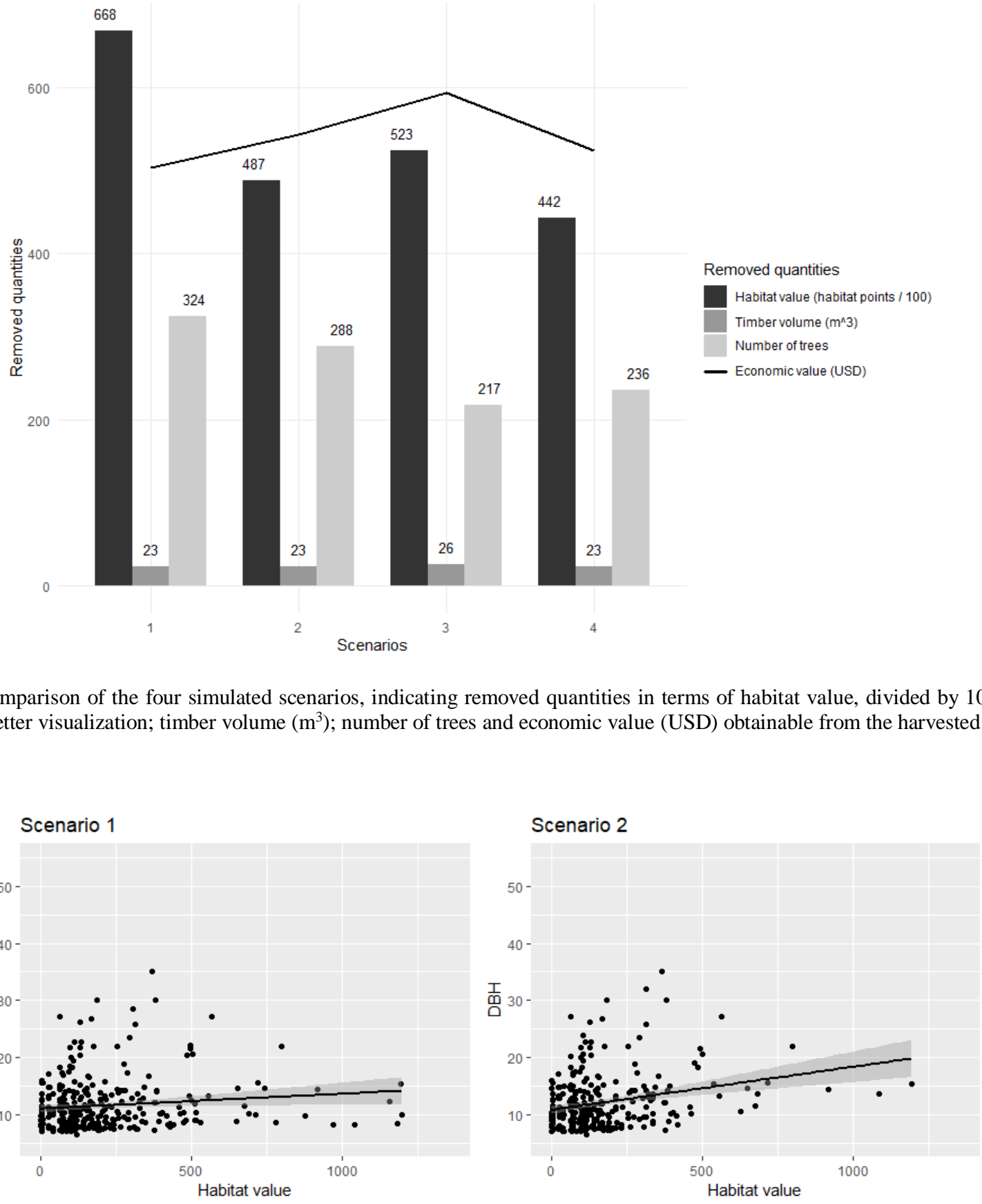

Scenario 3
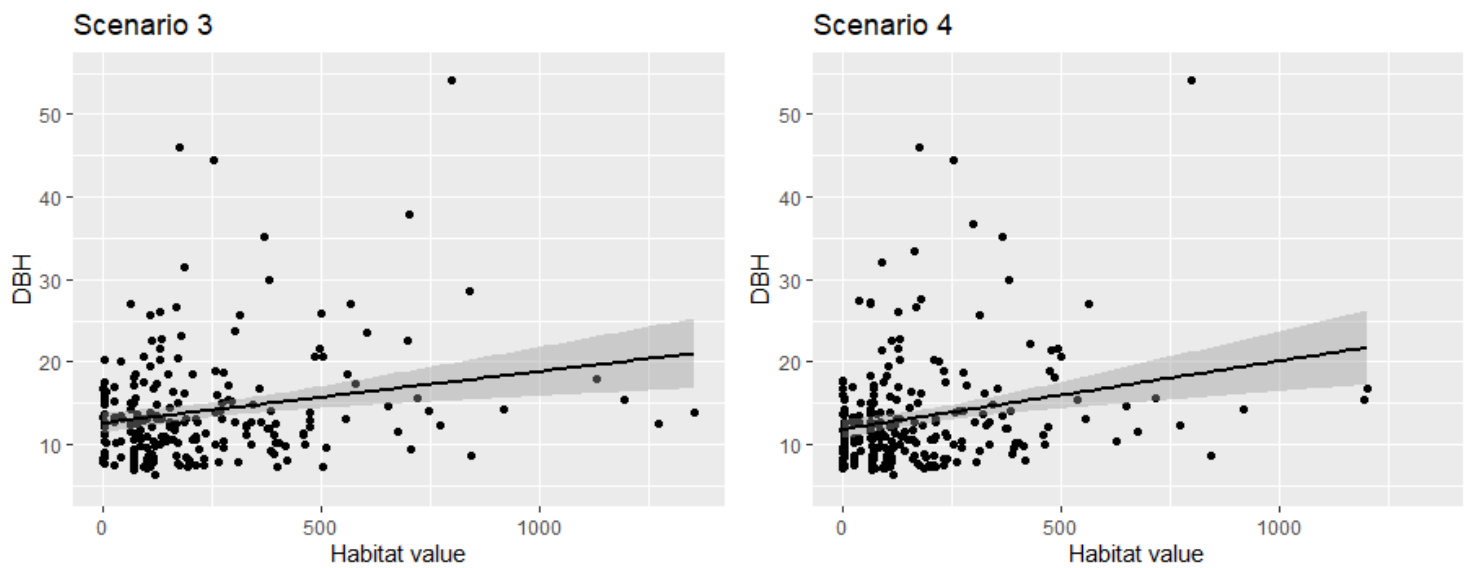

Figure 7. Relationship between DBH and habitat value of the marked trees in the four intervention scenarios 
Some of the TreMs described by Larrieu et al. (2018) (i.e. woodpecker cavities, fire and lighting scars, and perennial polypore) were not present in our plot. However, we did not find any TreMs types that were not classified in Table 1. Furthermore, in Larrieu et al. (2018), TreMs type groups are combined in a table that links each TreMs with one or more specific order of invertebrates and vertebrates. In our study area, we do not know if all those links coincide in the same way. This type of information would help us to understand exactly which orders are linked to each TreMs type.

Regarding nests, insect galleries, and boreholes, from the ground, it was not possible to verify the presence of vertebrate nests in the crown because of the high canopy density and the massive presence of lianas. However, termites were abundant on most of the trees and sometimes made their nests as galleries along with the bark and inside the stem (Yanagihara et al. 2018). This made it difficult to distinguish between insect-only galleries and insect galleries plus invertebrate nests. Furthermore, nesting inside the trees causes the two TreMs definitions to overlap: insect galleries and invertebrate nests become a single feature. During data collection, we tried to distinguish the two, but the difficulty of the task invites a degree of human error. Anyway, the effect of this error on the average tree habitat value should be low due to the low habitat value of both TreMs types.

We think that the uneven site characteristics across the study area explain the distribution of Pinus massoniana (Figure 5) since topographic variations in slope and orientation create different microclimates in the marteloscope. This also implies differences in solar radiation and soil characteristics (Holland and Steyn 1975; Noguchi et al. 1999), thereby favoring different tree species in different plot areas (Podwojewski et al. 2011). At the same time, those pines might have been spared in the last clear-cut that occurred in the 1990s. To verify these premises, we would need data about soil characteristics, solar radiation, and the age of the trees, which were not considered in the marteloscope set up. To understand the spatial distribution of Pinus massoniana, we should also consider past experience: the main reason why the forest plantation on this site failed in the 1990s, as explained in Paragraph 3.1, was because the species planted there (Acacia spp. and Pinus massoniana) were suppressed by more light-demanding species. Consequently, it could be that Pinus massoniana trees have remained in areas of relatively lower solar radiation in the plot.

\section{Economic and habitat values}

Economic and habitat values were the key elements in this research. The Vietnamese government identified 354 marketable tree species out of more than 4000 known species in Vietnam (The Names of Forest Plants in Vietnam 2000). Of the 58 tree species found in the marteloscope, only 19 are recognized as economically valuable according to the government list. Aside from that, economic value was calculated based on the value of the timber itself, without considering any additional harvesting costs that might reduce revenue. The data we used to define economic value is related to the buying price per cubic meter of each timber class. That data does not contemplate price variations that may occur as a function of tree characteristics such as diameter and straightness, or the presence of sap flows, trunk rot-holes, and other microhabitats. Many microhabitats are considered timber "defects" in that they logically reduce the amount of useful timber for industrial processing, which directly decreases the tree value.

Further attempts in literature review to discover more information about tree pricing of natural forests in Northern Vietnam were unsuccessful. This suggests a lack of data and constituted a limitation to our study. Given such considerations, we might assume that some trees that hostspecific microhabitats can be partially or totally used as firewood. We must also recognize that firewood in Vietnam and other developing countries is considered a free commodity, which may be collected without any other cost than that associated with the personal effort of gathering it (Kim et al. 2016). This reveals once more the differences between Mediterranean and tropical forests, as natural environments but also as socio-economical spaces. By comparing our study area with Southern Italy in the research of Santopuoli et al. (2019), we see how that study evaluated the price of firewood without even considering roundwood, which is not possible in our study area.

Furthermore, habitat value was assessed by the rarity, size, and development time of each TreMs type. Our results also showed that DBH can predict habitat value, as was found in previous studies involving Mediterranean and temperate forests (Michel and Winter 2009; Vuidot et al. 2011; Regnery et al. 2013; Asbeck et al. 2019; Santopuoli et al. 2019), but the correlation is weak (Figure 7). This suggests that more complex forest dynamics and factors interact to determine the TreMs type and the habitat value of the trees, which provides a challenge for future studies.

Finally, the average annual increment of the timber in the marteloscope is $5.25 \mathrm{~m}^{3} /$ year and $54 \%$ of it has economic value. Plantations for timber production of Acacia spp. in Vietnam are known to produce from 10 to $25 \mathrm{~m}^{3}$ per hectare each year over a ten-year period, which is also affected by the use of inputs such as fertilizers (Nambiar et al. 2015). The valuable timber production in the marteloscope was not comparable with that of an Acacia plantation.

\section{Thinning scenarios}

The different thinning scenarios showed very different results. When comparing S2 and S4, we see that the habitat value, number of trees, and economic value parameters were higher in S2. The timber volume was the same for both, as expected, because we were comparing the removal of suppressed vs. codominant trees and removed 52 trees less in S4 than in S2. It is very clear how removed TreMs after thinning was significantly reduced by including Criterion 2 in the tree selection. This can be appreciated both for the S1-S2 and the S3-S4 comparisons. The average habitat value of the marked trees within each scenario (Table 7) shows that $\mathrm{S} 1$ had the highest removed habitat value because we removed more trees to reach $30 \%$ of the 
basal area and the habitat value generally increases slightly with the DBH. The determining factor was the combination of the removed basal area and Criterion 1 about suppressed/codominant trees.

Finally, we would recommend the S4 approach of thinning from above rather than $\mathrm{S} 2$ thinning from below, as it implies removing 52 fewer trees but the same volume of timber. The removed economic value was also very similar (544 vs 524 USD), which makes S4 more efficient than S2 in terms of revenue per removed tree. The difference in the removed habitat value was negligible, amounting to 4500 habitat points $(2 \%)$ out of a total of 189,360 .

\section{Future perspectives}

Considering the results discussed above, this study has demonstrated the utility of estimating the habitat value of each tree within the marteloscope. We cannot say the same about estimating the economic value, which proved to be a debatable task. We also demonstrated how the TreMs criterion can be used as a proxy for biodiversity conservation in thinning plans. The comparison between economic benefit and TreMs conservation among the scenarios shows a win-win situation as the two objectives coincided.

This study also opens the door to other questions about how forest value will evolve in the future. For example, does high economic revenue today lead to less valuable timber in the future and take us back to the original issue of harvesting only high-value trees? The marteloscope is a good instrument for seeing the immediate effects of forest management; might it also be useful for medium-and longterm forecasting of tropical forest dynamics?

Our research compared habitat value and economic value for different thinning simulations, but it cannot predict forest response. By knowing which tree species have better chances for growth after the prescribed interventions, we might improve our understanding of this vast ecosystem and identify more precise guidelines for forest intervention.

In conclusion, higher habitat values corresponded to suppressed trees with low DBH. However, the general trend shows that TreMs and habitat values increased with increasing tree DBH. Forest protection policies in Vietnam made assessing the economic value of each tree highly debatable views: only $45 \%$ of the total number of trees was marketable for roundwood. Among the four thinning operations, the clear contribution of biodiversity conservation criteria in forest management led us to prefer S2 and S4 over S1 and S3. Of the two preferred scenarios, S4 proved to be the best option for biodiversity conservation. Though S3 was the best-performing scenario in terms of revenue and revenue per number of trees since it selected the most valuable trees, S4 still presented the best compromise between profit and habitat conservation.

\section{ACKNOWLEDGEMENTS}

Dr. Son Ho Ngoc, Deputy Dean of Forestry at Thai Nguyen University of Agriculture and Forestry, Vietnam, for providing logistical support. Dr. Chung Do Hoang, Dr. Hung Nguyen Tuan from the same department, for help with the marteloscope database. The BioEcoN project and Prof. Dr. Felipe Bravo Oviedo, coordinator of the University of Valladolid, Spain team, for providing this opportunity. The MEDFOR Erasmus+ Master Program, for financial support.

\section{REFERENCES}

Arndt U, Fomin A, Lorenz S. 1996. Bio-Indikation. Neue Entwicklungen, Nomenklatur, synökologische Aspekte.-Verlag G. Heimbach. [Germany]

Asbeck T, Pyttel P, Frey J, Bauhus J. 2019. Predicting abundance and diversity of tree-related microhabitats in Central European montane forests from common forest attributes. For Ecol Manag 432: 400-408. DOI: 10.1016/j.foreco.2018.09.043

Bradshaw CJ, Sodhi NS, Brook BW. 2009. Tropical turmoil: a biodiversity tragedy in progress. Front Ecol Environ 7 (2): 79-87. DOI: $10.1890 / 070193$

Chatham House. 2020. https://www.forestgovernance.chathamhouse.org.

Gardne TA, Barlow J, Chazdon R, Ewers RM, Harvey CA, Pere CA, Sodhi NS. 2009. Prospects for tropical forest biodiversity in a human-modified world. Ecol Lett 12 (6): 561-582. DOI: 10.1111/j.1461-0248.2009.01294.x

Gibson L, Lee TM, Koh LP, Brook BW, Gardner TA, Barlo J, Sodhi NS. 2011. Primary forests are irreplaceable for sustaining tropical biodiversity. Nature 478 (7369): 378. DOI: 10.1038/nature10425

Hinh VT. 2012. Phương pháp lập biểu thể tích thân cây rừng tự nhiên ở VN, NXB Nông nghiệp. http://vafs.gov.vn/vn/wpcontent/uploads/sites/2/2011/09/7-Tran-Son.bai-bao-1.pdf

Holland PG, Stey DG. 1975. Vegetational responses to latitudinal variations in slope angle and aspect. Journal of Biogeography, 179-183. DOI: $10.2307 / 3037989$

ITC [International Trade Centre ]. 2019. Calculations based on UN Comtrade statistics. http://www.intracen.org/itc/market-info-tools/trade-statistics/

IUCN. 2019. The IUCN Red List of Threatened Species. Version 2019-1. http://www.iucnredlist.org.

Jacobs M. 1976. The study of lianas. Flora Malesiana Bulletin 29 (1): 26102618.

Kim LTT, Nichols JD, Brown K. 2016. Firewood extraction and use in rural Vietnam: a household model for three communes in Ha Tinh Province. Agrofor Syst 91 (4): 649-661. DOI: 10.1007/s10457-016-9993-0

KimDung N, Bush S, Mol APJ. 2013. Administrative Co-management: The case of special-use forest conservation in Vietnam. Environ Manag 51: 616-630. DOI: 10.1007/s00267-012-0012-6

Kraus D, Schuck A, Krumm F, Bütler Sauvain R, Cosyns H, Courbaud B, Wilhelm G. 2018. Seeing is building better understanding-the Integrate+ Marteloscopes (No. REP_WORK). Integrate+ Technical Paper. University of Valladolid, Spain.

Larrieu L, Paillet, Y, Winter S, Bütler R, Kraus D, Krumm F, Vandekerkhove K. 2018. Tree related microhabitats in temperate and Mediterranean European forests: A hierarchical typology for inventory standardization. Ecol Indicat 84: 194-207. DOI: 10.1016/j.ecolind.2017.08.051

Magurran AE, Henderson PA. 2003. Explaining the excess of rare species in natural species abundance distributions. Nature 422 (6933): 714. DOI: 10.1038/nature01547

Meyfroidt P, Lambin EF. 2009. Forest transition in Vietnam and displacement of deforestation abroad. Proc Natl Acad Sci USA 106 (38): 16139-16144. DOI: 10.1073/pnas.0904942106

Michel AK, Winter S. 2009. Tree microhabitat structures as indicators of biodiversity in Douglas-fir forests of different stand ages and management histories in the Pacific Northwest, USA. For Ecol Manag 257 (6): 14531464. DOI: 10.1016/j.foreco.2008.11.027

Ministry of Agriculture and Rural Development \& Ministry of Trade, General Department of Customs, Hanoi. 1995. Bộ nông nghiệp và phát triển nông thôn-bộ thương mại-tổng cục hải quan.

Ministry of Agriculture and Rural Development, Hanoi. 2000. Tên cây rừng Việt Nam. Agriculture publishing house, Việt Nam.

Nambiar ES, Harwood CE, Kien ND. 2015. Acacia plantations in Vietnam: research and knowledge application to secure a sustainable future. Southern For J For Sci 77 (1): 1-10. DOI: 10.2989/20702620.2014.999301

Nguyễn TH. 2018. https://www.chucmungnammoi.vn/2017/12/tong-hop-banggia-tham-khao-cac-loai-go.html

Noguchi S, Tsuboyama Y, Sidle RC, Hosoda I. 1999. Morphological characteristics of macropores and the distribution of preferential flow pathways in a forested slope segment. Soil Sci Soc Am J 63 (5): 1413 1423. DOI: $10.2136 /$ sssaj1999.6351413x 
Podwojewski P, Poulenard J, Nguyet ML, De Rouw A, Pham QH, Tran DT 2011. Climate and vegetation determine soil organic matter status in an alpine inner-tropical soil catena in the Fan Si Pan Mountain, Vietnam Catena 87 (2): 226-239. DOI: 10.1016/j.catena.2011.06.002

Prime Minister of the Socialist Republic of Vietnam. 2007. Viet Nam Forestry Development Strategy 2006-2020 (Promulgated and enclosed with Decision No. 18/2007/Q-TTg, dated 5 February 2007).

Quang N, Ph T. 2005. Trends in forest ownership, forest resources tenure and institutional arrangements: are they contributing to better forest management and poverty reduction? The case of Viet Nam. http://www.fao.org/forestry/1058208d5469cf92f69afa4aa73e8843aff998.pdf

Regnery B, Couvet D, Kubarek L, Julien JF Kerbiriou C. 2013. Tree microhabitats as indicators of bird and bat communities in Mediterranean forests. Ecological Indicators, 34, 221-230. DOI 10.1016/j.ecolind.2013.05.003

Rocchini D, Ricotta C. 2007. Are landscapes as crisp as we may think? Ecological Modelling $204 \quad$ (3-4): 535-539. DOI 10.1016/j.ecolmodel.2006.12.028

Santopuoli G, di Cristofaro M, Kraus D, Schuck A, Lasserre B, Marchetti M. 2019. Biodiversity conservation and wood production in a Natura 2000 Mediterranean forest. A trade-off evaluation focused on the occurrence of microhabitats. iForest 12: 76-84. DOI: 10.3832/ifor2617-011

Schuck A, Krumm F, Kraus D. 2015. Integrate+ Marteloscopes-Description of parameters and assessment procedures. Integrate+ Technical Paper No. 18. $16 \mathrm{p}$.

Soucy M. 2014. Protocole d' installation des marteloscopes. "Horseback". DOI: $10.13140 /$ RG.2.2.32063.92326.
Tan NQ. 2006. Trends in forest ownership, forest resources tenure and institutional arrangements: are they contributing to better forest management and poverty reduction? case study from Vietnam. Understanding Forest Tenure in South and Southeast Asia-Forestry Policy and Institutions. FAO, Rome.

Thi Hoan L. 2014. Forest resources and forestry in Vietnam. J Vietnamese Environ 6 (2): 171-177.

United Nations. 1992. Convention on Biological Diversity. http://www.cbd.int/doc/legal/cbd-un-en.pdf

United Nations. 2015. Transforming our world: the 2030 agenda for sustainable development. http://www.un.org/ga/search/view_doc.asp?symbol=A/RES/70/1\&La $\mathrm{ng}=\mathrm{E}$

Vu LV. 2009. Diversity and similarity of butterfly communities in five different habitat types at Tam Dao National Park, Vietnam. J Zool 277: 15-22. DOI: 10.1111/j.1469-7998.2008.00498.x

Vuidot A, Paillet Y, Archaux F, Gosselin F. 2011. Influence of tree characteristics and forest management on tree microhabitats. Biol Conserv 144: 441-450. DOI: 10.1016/j.biocon.2010.09.030

Wilson KA, Auerbach NA, Sam K, Magini AG, Moss ASL, Langhans SD, Budiharta S., Terzano D, Meijaard E. 2016. Conservation research is not happening where it is most needed. PLoS Biol 14: e1002413. DOI: 10.1371/journal.pbio.1002413.

Yanagihara S, Suehiro W, Mitaka Y, Matsuura K. 2018. Age-based soldier polyethism: old termite soldiers take more risks than young soldiers. Biol Lett 14 (3): 20180025. DOI: 10.1098/rsbl.2018.0025 